\title{
Toe rock mass strength in footwall failures
}

\author{
A Duran PSM, Australia \\ D Cardona Lopez Prodeco, Colombia
}

\begin{abstract}
This paper presents results of check and back-analysis of highwall slopes and footwall instabilities in coal bearing sedimentary strata. The primary aim being to address the issue of rock mass strength at the footwall toe.

An issue highlighted previously by one of the authors is the often incomplete knowledge in a footwall scenario to enable analytically based design. Experience gained at coal mining operations in moderate to steeply dipping strata coupled with studies to resolve the unknowns has resulted in an understanding of the critical mechanism, shear strength on bedding defects, groundwater conditions and an approach to assessing the rock mass strength at the toe. This paper focuses on the latter aspect of toe rock mass strength. The results question the applicability of studies suggesting the use of the disturbance factor associated with unloading of slopes to sedimentary strata. The methodology proposed by the authors for the footwall toe rock mass strength to account for anisotropy is to accept a disturbance factor of zero and downrate the Geological Strength Index (GSI) value. Furthermore, the authors caution against the use of the GSI fissile molasse chart for coal bearing strata unless there is significant tectonic deformation of the rock mass evident at the small-scale.
\end{abstract}

Keywords: footwall, steep dips, coal mining, rock mass strengths, disturbance factor, back-analysis

\section{Introduction}

Once the typical dip of coal seam strata exceeds $10^{\circ}$ (for discussion purposes less than $10^{\circ}$ is referred to as shallow dips in the following text) open cut coal mining is usually undertaken utilising truck and shovel mining techniques. Truck and shovel mining development proceeds in terraced panels with formation of a highwall (where strata dips into the wall), endwalls (either as a final wall or part of the advancing terrace), a footwall and where space permits backfilling of the established void. Depending on the dip of strata, the footwall may either follow the floor of the target coal seam (particularly where dips remain moderate, $10-15^{\circ}$, to steep, $15-25^{\circ}$ ) or require a benched profile, which may require mining of under-burden (typical once dips are very steep, in excess of $30^{\circ}$ and dependent on overall height of slope).

Footwall stability and particularly where it is unbenched is a key safety and productivity concern when mining coal seams with steep dips. The speed of collapse and the volumes of material present a severe safety hazard. Operationally re-establishing access to the target seam is complex and the alternatives may involve a step-in to a less desirable seam, a cutback or cessation of mining in the panel.

Stead \& Eberhardt (1997) provides a detailed review of footwall failures and propose four mechanisms: active/passive, quasi rotational, toe release involving shear through intact rock and complex involving buckling and/or ploughing. A key aspect in such failures is the requirement for a discontinuity below the mined floor that has significant continuity to allow formation of what the authors' term slab failures. Such discontinuities may comprise bedding surfaces, clay seams or tuff layers. Tectonic deformations are commonly associated with coal basins where moderate to very steep dips are present, so it is possible that discontinuities are sheared with the formation of slickendsided surfaces. An understanding of the stratigraphic location of the 'weak' bedding parallel features and their character is paramount to design an adequately stable footwall. 
Numerous methods of analysis of the slab type failures can be used and in summary these comprise:

- Buckling type analysis as initially proposed by Kutter (1974) and further elaborated upon by Cavers (1981) and Garzon (2016).

- Closed-form solutions by Hawley et al. (1986) and more recently Alejano et al. (2011).

- Finite element (FE) techniques such as Coulthard et al. (2004), and limit equilibrium (LE) techniques involving the method of slices.

This paper presents the experience gained in the Prodeco coal mines of northwest Colombia over the last 10 years. Results of check analysis of highwalls and back-analysis of footwall instabilities carried out by the authors using LE analysis are presented. These have been utilised to assist in providing appropriate footwall designs for coal mining in moderate to steeply dipping strata.

\section{$2 \quad$ Key drivers in footwall stability}

Experience with footwall instabilities have largely shown that of the four mechanisms proposed by Stead \& Eberhardt (1997), toe release involving shear through intact rock is most commonly observed in the Prodeco operations. There are five key drivers or issues which need to be understood when developing footwall slope designs including:

1. Footwall geometry.

2. Stratigraphic location of weak layers.

3. Shear strength of weak layers.

4. Toe rock mass strength.

5. Groundwater.

\subsection{Geometry of footwall}

The footwall, key coal seams and overall geometry is defined by resource drilling. Drilling density to adequately define coal resources in alignment with Joint Ore Reserves Committee (JORC) Code standards has been found to provide cross-sectional models which are in good agreement with as mined geology. The exception is where tight large-scale folding is present, and where modelling tends to underestimate the tightness of the folding and definition of the fold axis.

Experience at Prodeco has typically been that small-scale faults are uncommon, and drilling supports definition of significant and major faults.

\subsection{Stratigraphic location of weak layers}

Experience has shown that sliding of the footwall slab occurs on weak layers (clay seams, tuff layers or bedding parallel shears) within the stratigraphy. The geotechnical character of bedding partings is such that they provide a much higher shear strength than the weak layers. Hence potential footwall instability is governed by the presence of the weak layers. The location of these weak layers is typically stratigraphically bound. As such, slope design should focus on specific locations rather than assuming a ubiquitous model of occurrence in the footwall. Assuming a ubiquitous model results in an overly conservative footwall design owing to the acceptance of very thin slabs that offer little rock mass toe strength.

At Prodeco, experience is that sliding occurs on clay seams often with thickness less than one centimetre. The thin clay seams are difficult to reliably assign in core drilling and can be difficult to clearly demarcate in geophysical logging. The clay seam stratigraphic occurrence at each Prodeco site has been confirmed through a combination of historic instability, core drilling, geophysics and through deformations observed in boreholes extensometers installed in key areas of footwalls. 
Having defined these locations allows for development of appropriate designs, and also critically ensures that where benched designs may be warranted, that the under-benching targets mining out of the clay seams rather than leaving thin remnant slabs.

\subsection{Shear strength of weak layers}

Owing to the clay seams being thin, and difficult to recover in diamond core drilling, there are significant difficulties in collecting appropriate samples for laboratory testing. To highlight the issues that may be encountered Figure 1 presents laboratory direct shear strength testing of bedding parallel samples to 2005 from one Prodeco site.

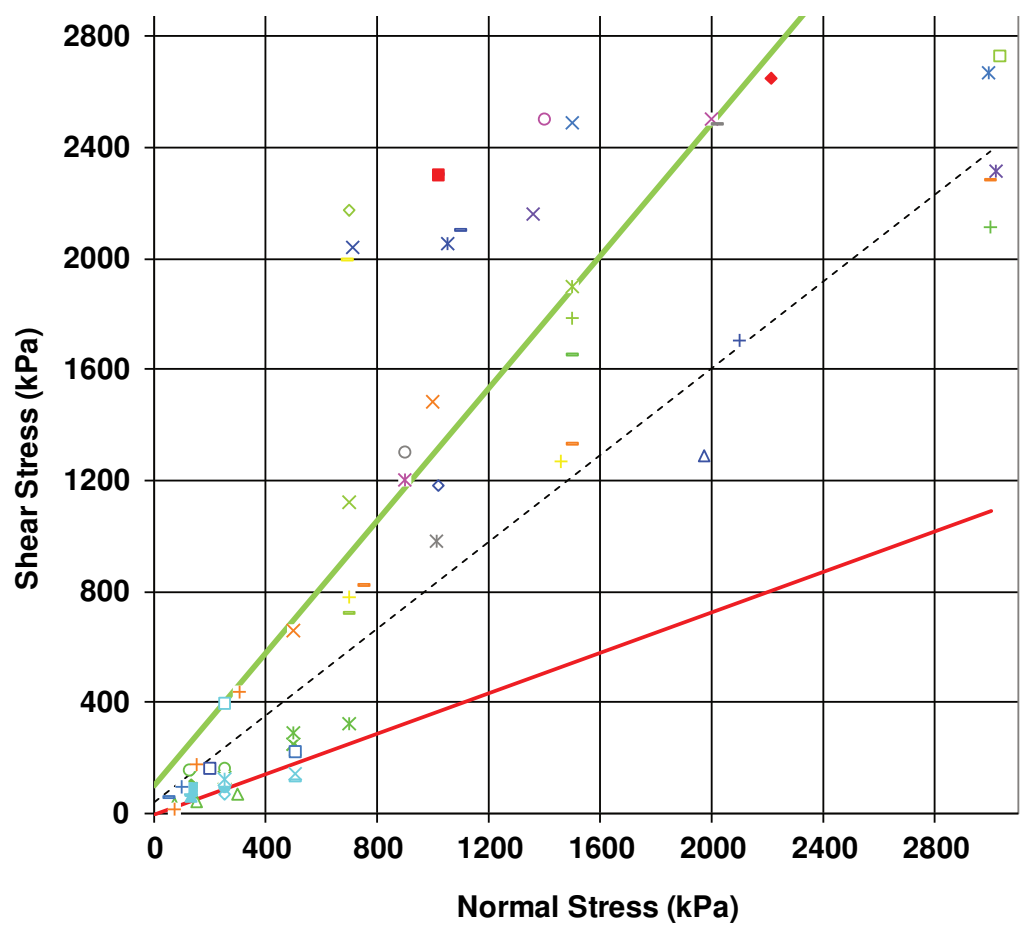

Figure 1 Direct shear strength testing to 2005

Interpolation from Figure 1 suggests a wide range of possible shear strengths, whilst a reasonable lower bound to the testing can be applied (red line with zero cohesion and friction angle of $20^{\circ}$ ) the upper bound is poorly constrained. An upper bound strength is shown in green (with cohesion of $100 \mathrm{kPa}$ and friction angle of $52^{\circ}$ ) but there is testing with even higher shear strengths. Review indicated that much of the testing above the dotted line in Figure 1 was from 'saw-cut' surfaces and highlights the inherent issues with such testing.

Additional testing was subsequently undertaken, with careful attention to recovering and testing the clay seams. Figure 2 provides an update of the available testing and with removal of all 'saw-cut' test results. Whilst a range of results is still evident, the range is smaller than Figure 1 and the data suggests a lower bound with zero cohesion and a friction angle of $13^{\circ}$ and an upper bound of cohesion of $40 \mathrm{kPa}$ and friction angle of $25^{\circ}$. The authors have seen numerous approaches in the manner in which to assess appropriate design parameters and these may include: assessing a cohesion and friction angle for each test result and taking the respective means of cohesion and friction angle, regression to the testing or adopting a 'lower quartile' strength. The former approach is not appropriate with the Prodeco data as there was only a handful of multi-stage tests and the majority single stage testing. A regression indicates a cohesion of $42 \mathrm{kPa}$ and friction angle of $17^{\circ}$ whilst a lower quartile approach provides a cohesion of $10 \mathrm{kPa}$ and friction angle of $16^{\circ}$.

The lower quartile approach has been adopted at Prodeco although a zero cohesion has been adopted and in view that the large-scale folding of the strata is likely to have brought the clay seams to residual conditions. 


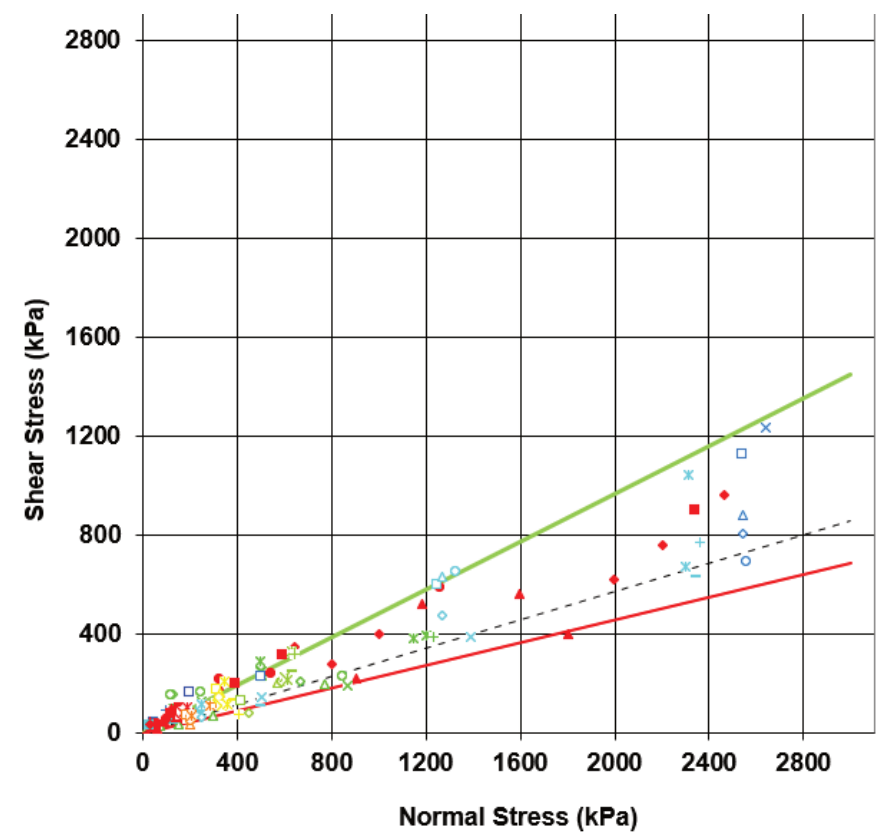

Figure 2 Updated direct shear strength testing with saw-cut surfaces ignored

As should be evident with either of the approaches in assigning design parameters, judicious removal of questionable testing is often required and hence the potential for bias.

\subsection{Toe rock mass strength}

The rock mass quality and rock mass strength applied at the toe is a critical aspect for footwall slopes. The comments by Hawley et al. (1986, p. 51) are worthy of repeating:

"In most cases, the confidence with which rock mass strength can be predicted determines the accuracy of the stability analysis, not the analysis technique used.

Assessment of rock mass strength may be based on semi-empirical techniques or back analysis of existing slopes. Any estimate or rock mass strength must recognise the highly anisotropic nature of the rock due to the presence of bedding discontinuities."

Currently the only readily available transparent approach to assessing rock mass strength is the Geological Strength Index (GSI). Whilst the rock mass quality in the toe is highly reliant on review of borehole core, the degree of similarity with the rock mass above and which can be viewed in highwall exposures allows for a check on design assumptions.

Initially three methods were utilised initially to assess rock mass quality for the Tertiary aged coal bearing sediments, typically comprising $55 \%$ sandstone, $25 \%$ siltstone and $20 \%$ claystone and these included:

1. Assessing rock mass rating (RMR) from the borehole core using Bieniawski's (1989) approach and applying the equivalence to GSI as noted in Hoek \& Brown (1997).

2. Using Hoek et al. (2005) and accepting the coal bearing sediments, as fissile molasse.

3. Using Hoek et al. (2005) and accepting the coal bearing sediments as molassic rock in a confined state.

The GSI assessments as a result of the three methods provides the following nominal GSI estimates of the rock mass at Prodeco:

1. GSI of 55-60.

2. GSI of $40-45$ (Sectors M4/M5 in the fissile molasse chart of Hoek et al. 2005).

3. GSI of 60-65 (lower half of Sector M1 in confined molasse chart of Hoek et al. 2005). 
It is interesting to note the significantly lower GSI if one adopts method 2. Hoek et al. (2005) recommends that method 2 is mainly applied for surface excavations (slopes) whilst method 3 is mainly applicable for tunnels. Whilst methods 1 and 3 provide somewhat similar estimates, method 1 is routinely utilised at Prodeco in rock mass quality estimation.

Estimates of rock mass strength using the approach of Hoek et al. (2002) are incorporated in the stability analyses using the GSI estimates, coupled with intact strength and the mi parameter respectively from laboratory uniaxial compressive strength and triaxial testing and the disturbance factor (D).

Separate from the requirement to assume isotropy, $D$ is considered by the lead author to be somewhat troubling and specifically in light of experience with slope stability in sedimentary deposits. To highlight this aspect, the recommendations of $D$ values as proposed by Hoek \& Brown (2018) regarding slopes and those of Rose et al. (2018) have been utilised in this paper. For the rock mass at Prodeco, the use of Rose et al. (2018) would suggest disturbance rating (DR) values of 33 in the footwall and 20 in the highwall. The implications of these DR values are discussed in Section 4.2

\subsection{Groundwater}

Groundwater is typically the least understood of all inputs into slope stability. Whilst considerable effort is spent on rock mass characterisation, laboratory testing, development of a geotechnical model and analysis to support designs, groundwater is typically treated as an afterthought often with limited data and based on sketchy assumptions. The authors consider this aspect offers the greatest uncertainty in the designs. Moreover, there can be dramatic impacts on footwall stability, even on what appear as relatively minor increases in groundwater levels in a footwall setting. As such, Prodeco seeks to reduce porewater pressures using either shallow vertical wells or horizontal drain holes installed progressively in each mining lift together with a regular grid of piezometers in the advancing footwall to ensure pore pressures in the footwall are appropriately understood.

As noted in Duran \& Seedsman (2018) footwall failures often occurred during or immediately after heavy rain events. In view of limited piezometer data during initial mining at Prodeco, it was postulated that transient water pressures in dilated discontinuities below the floor of the coal seams was a primary trigger to the failures. Figure 3 provides the concept and with rainfall introducing water pressures in the dilated surfaces that may become artesian towards the toe. It is noteworthy that this hazard was also identified by Cavers et al. (1986).

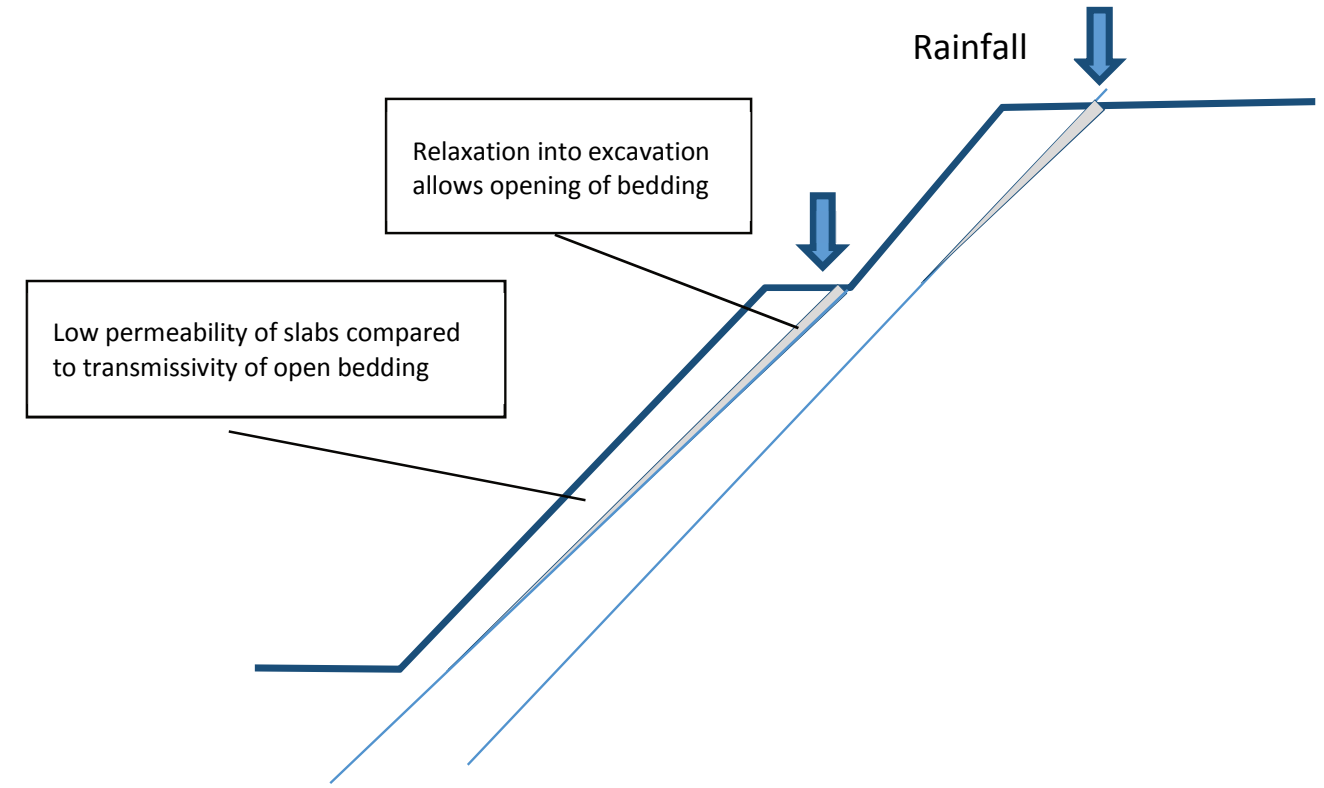

Figure 3 Possible transient water pressures in footwall 
As mining has progressed at each project, multi-tip vibrating wire piezometers have been installed in the footwalls to better understand the piezometric conditions and potential transient responses. These instruments have shown several interesting trends, including:

- Initial depressurisation in response to vertical relief wells.

- Whilst there are increases in pore pressure, there is no evidence of rapid transient responses to rainfall (Figure 4). This data is from a piezometer with a datalogger set to capture data on a 30 minute interval. The rapid 'spike' on the piezometer at $17 \mathrm{~m}$ depth on 29 May relates to the tip being 'sheared off'.

- Non-hydrostatic conditions within the footwall slab. For the example in Figure 4, and as evident in the margin sketch at left with top two piezometers dry (bracket highlighting range is response over time of lower piezometers) and with a downward gradient indicated in the lowest two piezometers.

- Trends of delayed response to rainfall (Figure 4).

- Pore pressures retreating to earlier levels in some piezometers (Figure 4).

- However, lowest piezometer showing a progressive upwards increase in pore pressure (Figure 4).

Interestingly in this case and in a previous case, the latter behaviour of progressive upwards increases was a precursor to instability. The authors consider the progressive upwards increases as highlighting recharge and re-pressurisation in the footwall slab.

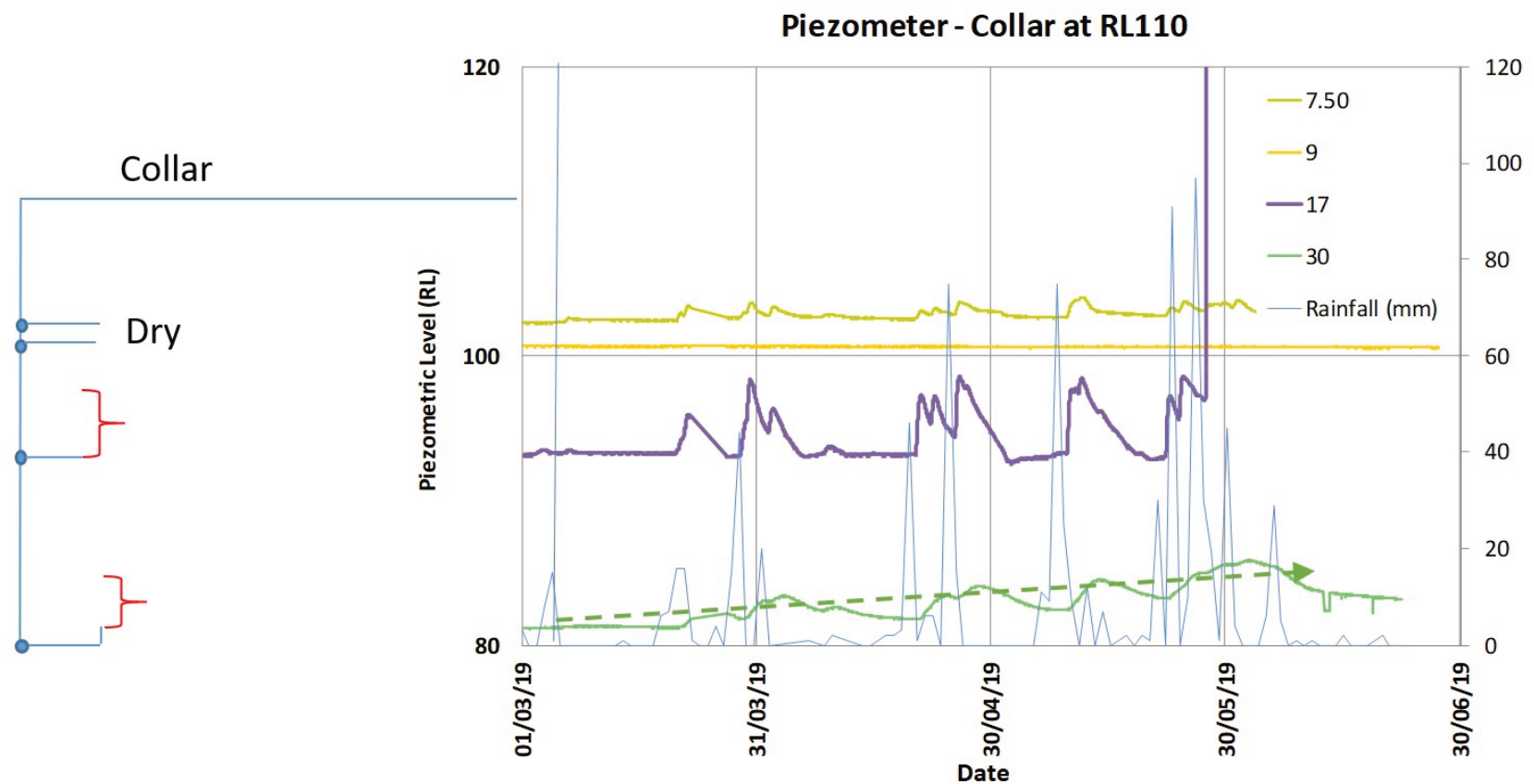

Figure 4 Typical responses observed in piezometers with daily rainfall plotted. Sketch at left highlights piezometer tip placement (blue dots) and range of head levels above the tip (red bracket)

Interestingly the response in adjacent panels can vary from this example (Figure 4), often indicating near saturated conditions in the footwall. Such changes in behaviour do not appear linked to major structures or changes in rock mass character in the footwall. As such, the adequacy of using groundwater modelling to provide input into stability analyses is somewhat questionable.

\section{$3 \quad$ Limitations with inputs to footwall analyses}

During initial studies in assessing stability of the footwall, the authors recognised the difficulty in selecting design parameters to allow footwall designs through stability analyses, Duran \& Seedsman (2018). Two significant limitations were attributed to the difficulty and these included the issues of anisotropy in the 
footwall toe and potential limitations with LE techniques. Whilst FE techniques remove the potential limitations with LE techniques they do not resolve the issue of anisotropy and are more time consuming to apply. From the viewpoint of operations which needs to often look at multiple design options in a timely fashion LE techniques are better suited.

\subsection{Potential limitations with limit equilibrium analyses}

A key assumption in LE analysis is that the normal stress applied to the base of each slice follows a smooth trend and approximately equal to that related to the height of the slice (Krahn 2003). LE methods may not be readily applicable for footwall analyses owing to the high stress concentrations at the toe. Figure 5 presents a contour plot of the minor principal stress developed in a footwall slab, which is basically the same stress as the normal stress on the base of the sliding mechanism. The footwall slab geometry and properties are in keeping with the case presented by Coulthard et al. (2004). It can be readily seen that there is a significant reduction in stress towards the toe of the slope and this may aid to highlight that stability may be lower than that indicated by LE models. Note red line on axes in Figure 5 represents same $\mathrm{X}$ axis interval.

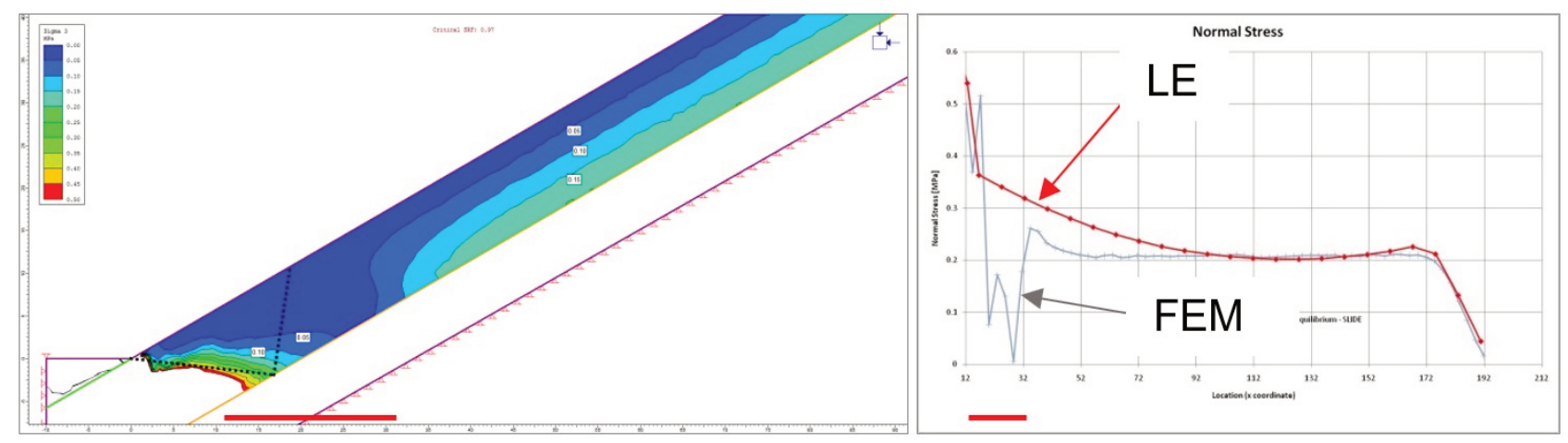

Figure 5 Difference between finite element and presumed stress magnitudes along the failure surface

\subsection{Limitations with Geological Strength Index - anisotropy}

When the GSI was introduced, Hoek \& Brown (1997) emphasised that the failure criterion assumes isotropic rock mass behaviour. While this may be a valid assumption for igneous and metamorphic (often referred to as hard) rocks it is less tenable for sedimentary (soft) rocks and especially the thinly bedded siltstones and sandstones that are typically found in coal bearing sedimentary strata. Bedding introduces transverse anisotropy that not only impacts on strength but also on how stresses are concentrated around openings.

To address the problem of transverse anisotropy within the Generalised Hoek-Brown criterion the authors have found that the rock mass strength needs to consider the direction of loading with respect to bedding, Seedsman (2017). When considering a rock mass failure in a highwall the loading tends to be at a high angle to the bedding and the 'full' rock mass strength is appropriate. However, for footwall analyses and specifically at the toe, wherein loading direction is at a much lower angle to bedding, a proportion of the full rock mass strength needs to be considered. There are available anisotropic models which proportion between $100 \%$ rock mass and $100 \%$ bedding shear strength based on direction of loading (Mercer 2012; Tokimoto \& Mercer 2013). To avoid the issue of the anisotropic model assumptions having a large bearing on stability analyses, the authors utilise a simplified model, Figure 6, and where a proportion of the full rock mass strength (green line) is utilised for the footwall slab rock mass and clay seams modelled implicitly for footwall stability analyses. There is limited experience as to how the proportioning of the full rock mass strength should be addressed. 


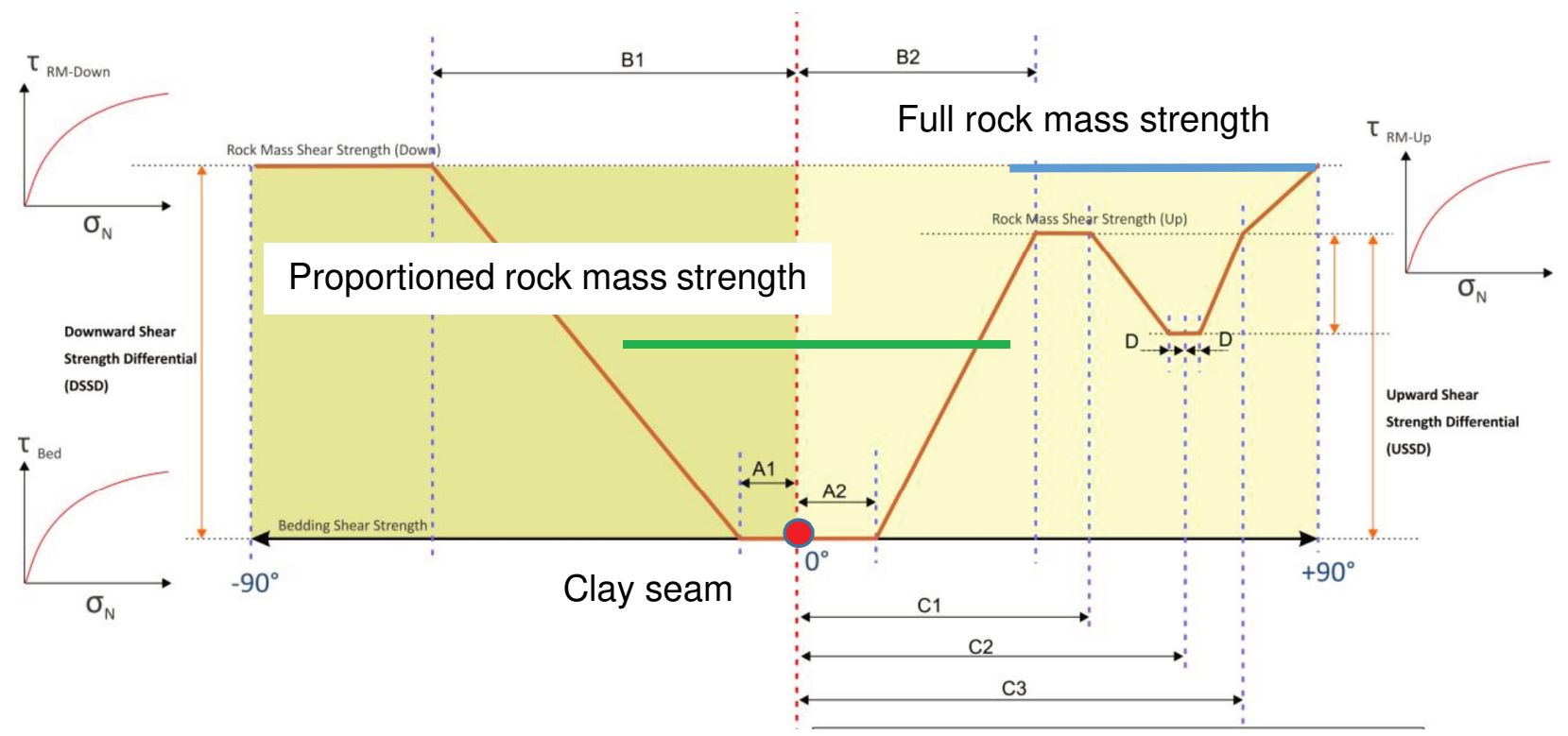

Figure 6 ALM3 model after Mercer (2013), and authors assumptions in LE analyses (red dot and green line for footwall analyses, blue line for highwall analyses)

\section{$4 \quad$ Check and back analyses}

\subsection{Check analyses highwall}

Check analyses provide a confirmation on the plausibility of input parameters for an analysis but do not always provide firm bounds such as a back-analysis and wherein a Factor of Safety (FOS) of near unity is implied. As a case in point, a check analysis was carried out on a highwall at the Prodeco operation which represents the highest highwall developed to date and which shown no signs of adverse deformations based on visual observations and radar monitoring. As such, from a stability point of view it could be argued that the FOS of the slope is higher than 1.10, unlikely to be lower but clearly no upper bound on FOS can be implied. The highwall has one multi-tip piezometer near the crest and in view that there is little evidence of seepage at the toe allows the groundwater conditions in the analysis to be reasonably bound.

Check analyses were carried out, with key interburden units assigned in the slope. Logging and laboratory testing indicated that there was limited variation in GSI (typically 55) throughout the interburdens. However, the proportion of sandstone and siltstone in each interburden varied and hence resulting in differences in the mean intact strength for each interburden. In the model, each interburden was sub-divided with three zones of different $D$ values, in keeping with the guidelines provided in Rose et al. (2018). Strictly speaking additional zones of decreasing $D$ values could be introduced into the left part of the model. However, the failure path for the critical FOSs were within the three provided zones and hence further sub-division would be of limited value.

Two analyses were carried out and with GSI estimates based on method 1 (based on RMR from logging and providing a GSI of 55) and method 2 (approach in Hoek et al. (2005) fissile molasse chart and providing a GSI of 45 ). The analysis with a GSI of 55 provided a FOS of 1.19, Figure 7, and in view that the slope has not shown any signs of distress the input parameters are reasonable. One could also argue that higher rock mass strength parameters may also be present. The analysis with a GSI of 45 provided a FOS of 0.92 and suggests that the use of the fissile molasse chart is inappropriate for undeformed coal bearing sedimentary rocks. 

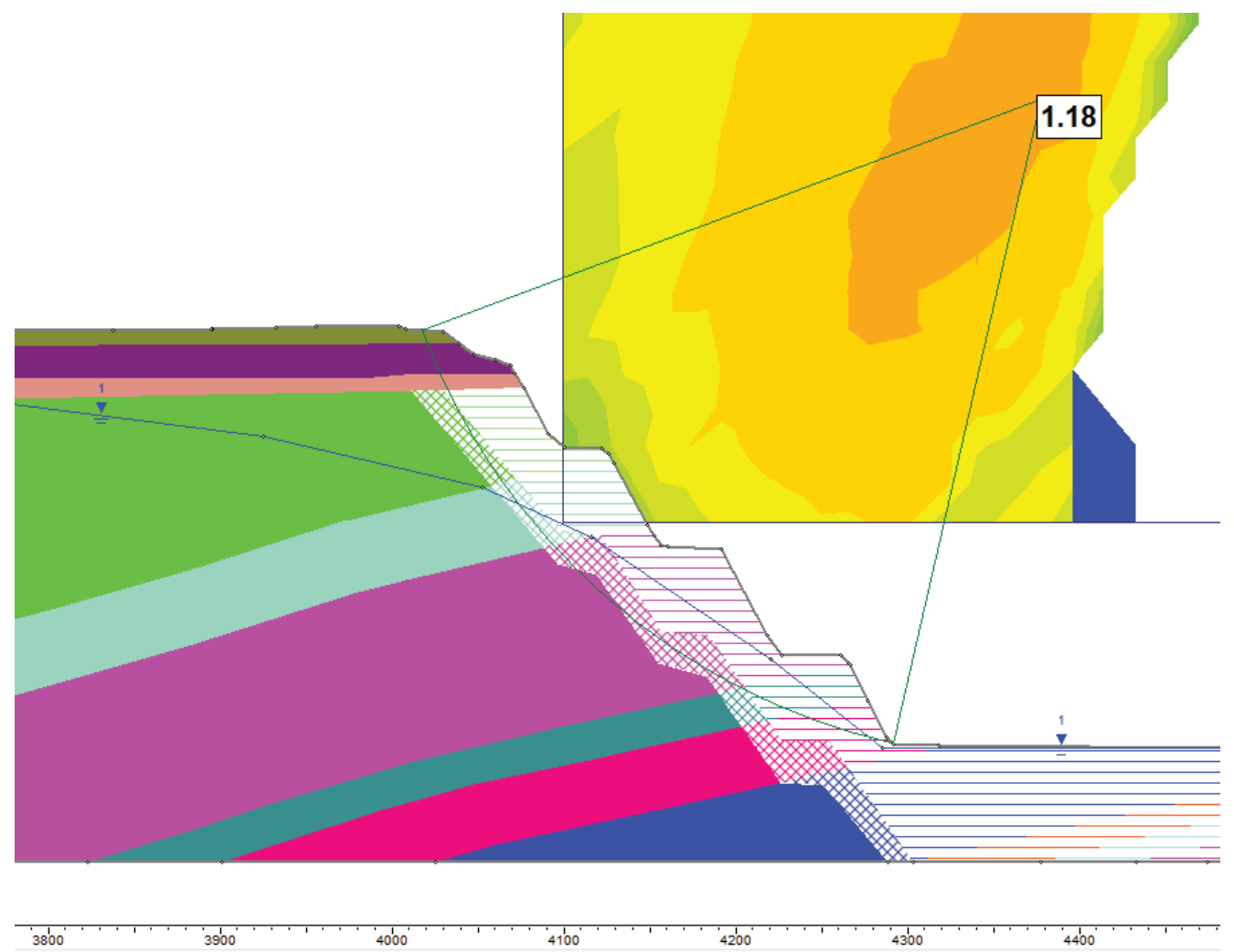

Figure 7 Check analysis of highwall, solid coloured zones with D of 0.75 , cross-hatch zones with D of 0.85 and horizontal-hatch with $\mathrm{D}$ of 1.0

\subsection{Preliminary back analyses footwall}

Whilst there is a history of footwall failures at the Prodeco operations, the initial failures had a very limited understanding of groundwater conditions. Issues with initial back-analyses are discussed in Duran \& Seedsman (2018) regarding one of these failures. The current authors have utilised back-analysis of six of the early failures to arrive at a view of toe rock mass strength parameters for design purposes.

Groundwater assumptions for these earlier failures have assumed a near saturated slope in the upper part of the slope and with minor artesian pressures at the toe, Figure 8. Artesian pressures at the toe are warranted in view of the discussion above and in consideration that during initial mining there were limited depressurisation measures. The authors note there is a physical limit on the artesian pressures that can develop in the toe as deformation, cracking and joint opening would lead to dissipation of excess pressures.

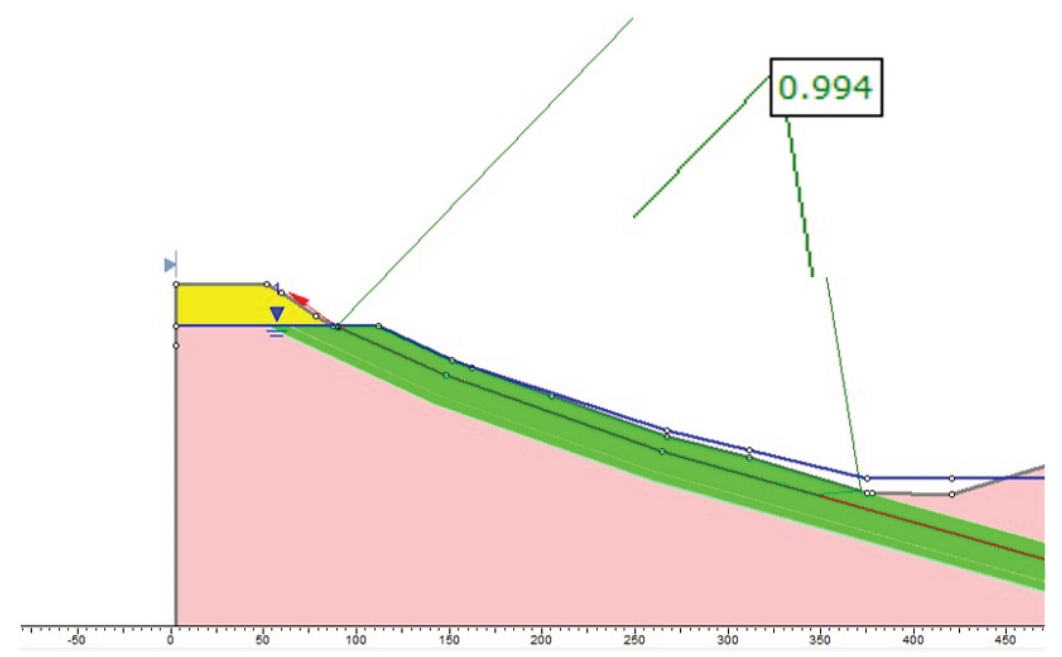

Figure 8 Typical groundwater assumptions for preliminary back-analysis 
A key aspect of the preliminary back-analyses was the toe rock mass strength required and the assumption of the value of D. Table 1 provides an overview of FOSs achieved as a result of different combinations of applied GSI and D for the slope in Figure 8. Two different values of GSI were utilised in the analyses, a GSI of 58 and which relates to method 1 (based on RMR from logging in the footwall slab) and a GSI of 45 which relates to method 2 (Hoek et al. (2005) fissile molasse chart). Note the footwall slab thickness, based on clay seam location, is only $10 \mathrm{~m}$ and based on guidance in Hoek \& Brown (2018) and Rose et al. (2018), D values of 0.7 or 1.0 are respectively indicated. Back-analyses with a $D$ value of zero are also presented.

Table $1 \quad$ Summary of back-analysis results

\begin{tabular}{lcccccc}
\hline Parameter & & & & & & \\
\hline GSI & 45 & 45 & 45 & 58 & 58 & 58 \\
D & 0 & 0.7 & 1.0 & 0 & 0.7 & 1.0 \\
FOS & 1.00 & 0.66 & 0.53 & 1.36 & 1.00 & 0.83 \\
\hline
\end{tabular}

The above trend of FOS results was largely repeated for the other five back-analyses which provided a range of slope heights and slab thicknesses (as in some cases a deeper clay seam was found to be more critical to stability) to allow bounds on the inputs. Whilst there was poor knowledge on actual groundwater conditions, input assumptions were largely in keeping with Figure 8. The back-analyses highlight that possible combination include either; GSI of 45 with a D of zero or GSI of 58 with a D of 0.7 as being applicable for footwalls at Prodeco. These two alternative views are at odds with the discussions above regarding the results of highwall check analyses, D values as suggested by Hoek \& Brown (2018) and Rose et al. (2018) and the impact of anisotropy on the toe rock mass strength.

A significant concern the lead author has with the concept of the disturbance factor for the larger scale rock mass is the point that it relates to relaxation of stress. Concerns comprise:

- Some of the cases presented in Rose et al. (2018) are of a toppling mechanism. Such cases involve significant strain induced disturbance as a result of the underlying mechanism of movement during mining of the slope. As such, it is questioned: is the overprinting of $D$ on the rock mass an attempt to account for the movements (calibrated to displacement) but do they have a bearing on the actual rock mass strengths (calibrated to failure)?

- In coal bearing sedimentary strata it could be argued the sequence was lithified under burial depths of the order of $2-3 \mathrm{~km}$. Subsequently, during the process of uplift the stress relaxation incurred overwhelmingly exceeds the stress removal that occurs as part of the mining process. As such, this implies that a $D$ value of 1.0 is applicable for the entire slope prior to mining.

- The calibration that underpins the Hoek-Brown Criterion for rock masses, Hoek \& Brown (1980), is based on recompacted samples in a large triaxial cell. These tests essentially have a $D$ value of 1.0. The concept of disturbance was not considered till much later, Hoek et al. (2002). The Hoek and Brown Criterion equations were not revised in light that the recompacted samples are disturbed.

- High D values may be rationalised for the immediate pit wall where blast damage is evident as there is an increase in fracturing and additional freedom for block movement. However, the concept is highly puzzling for the rock mass behind the slope and which remains confined.

- In the authors experience core drilling from a pit and into the pit wall, hence traversing the disturbed zone, should indicate signs of disturbance through lower rock quality designation (RQD), more open fractures or potentially lower sonic velocities in geophysics. However, such core drilling (apart from several metres through initial blast damage) largely shows no difference to the character seen in core that was drilled from surface prior to mining commencing. 
In light of the above, the authors argue that a $D$ value of zero for the rock mass behind the immediate zone of blast damage is appropriate. In the highwall at Prodeco the blast damage zone may be of the order of $3 \mathrm{~m}$ and in line with the $30 \%$ of the height (over which blasting is carried out) Hoek \& Brown (2018) and with GSI values of 55 to 65 applicable. For the footwall, blasting stops just above the coal seam, with significant attenuation through the coal, such that there is no blast damage in the footwall and where a D of zero is applicable. The authors therefore consider that in the footwall analyses, the lower GSI of 45 relates to the impact of anisotropy on the toe rock mass strength.

\subsection{Detailed back analyses footwall}

Two further back-analyses were carried out and for footwall slopes where piezometer monitoring was available to better control input assumptions. This coincided with Prodeco installing a regular grid of piezometers in the advancing footwall.

The back-analyses are presented in Figures 9 and 10 and represent significant differences in footwall height, bedding dips and groundwater assumptions. Of interest in both cases, one at each Prodeco site, are the variances in the groundwater. A FOS higher than unity was accepted for the latter case in view that extensometers were indicating excessive movements, but the slope did not fail. Subsequent buttressing at the toe area through backfilling resulted in cessation of movements of this slope. Both back-analyses both utilised a similar GSI ( 42 and 44 respectively) for the footwall toe to that in the preliminary back-analyses and with a $D$ value of zero.

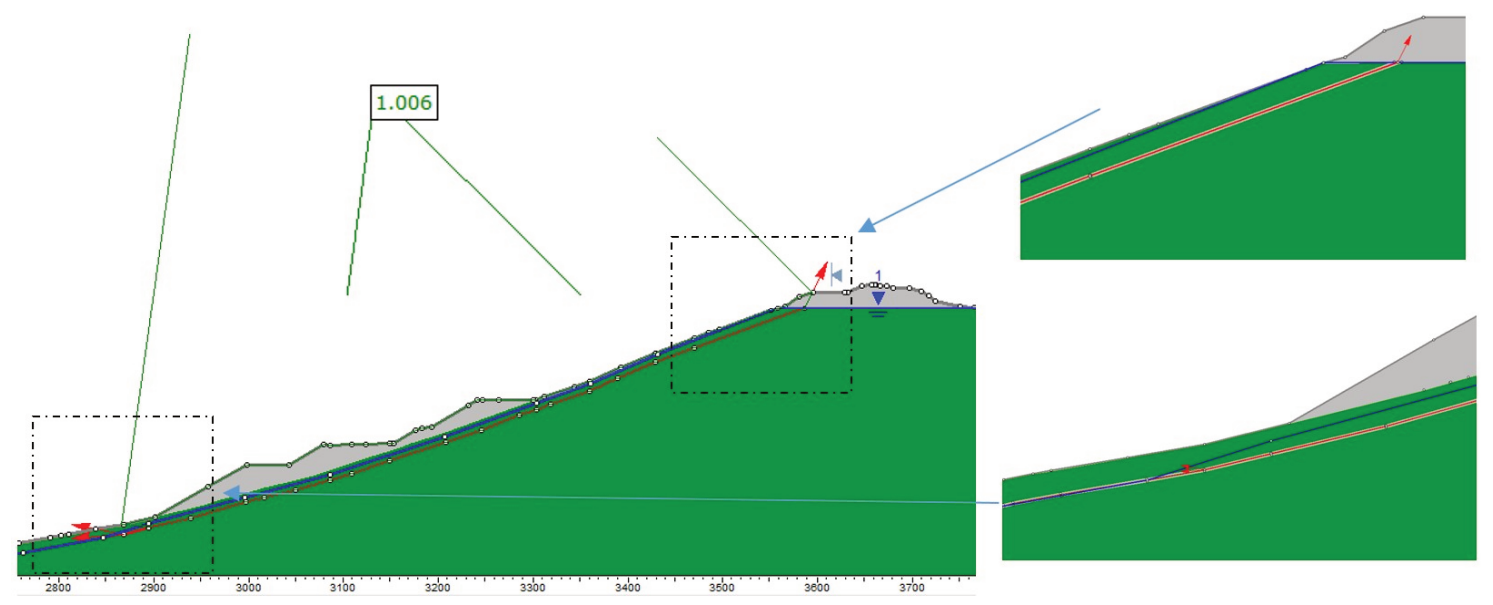

Figure 9 Back-analysis of significant footwall failure, note depressurised footwall in toe area (lower right) and saturated at crest area (upper right) and backfilling (grey) perched on footwall

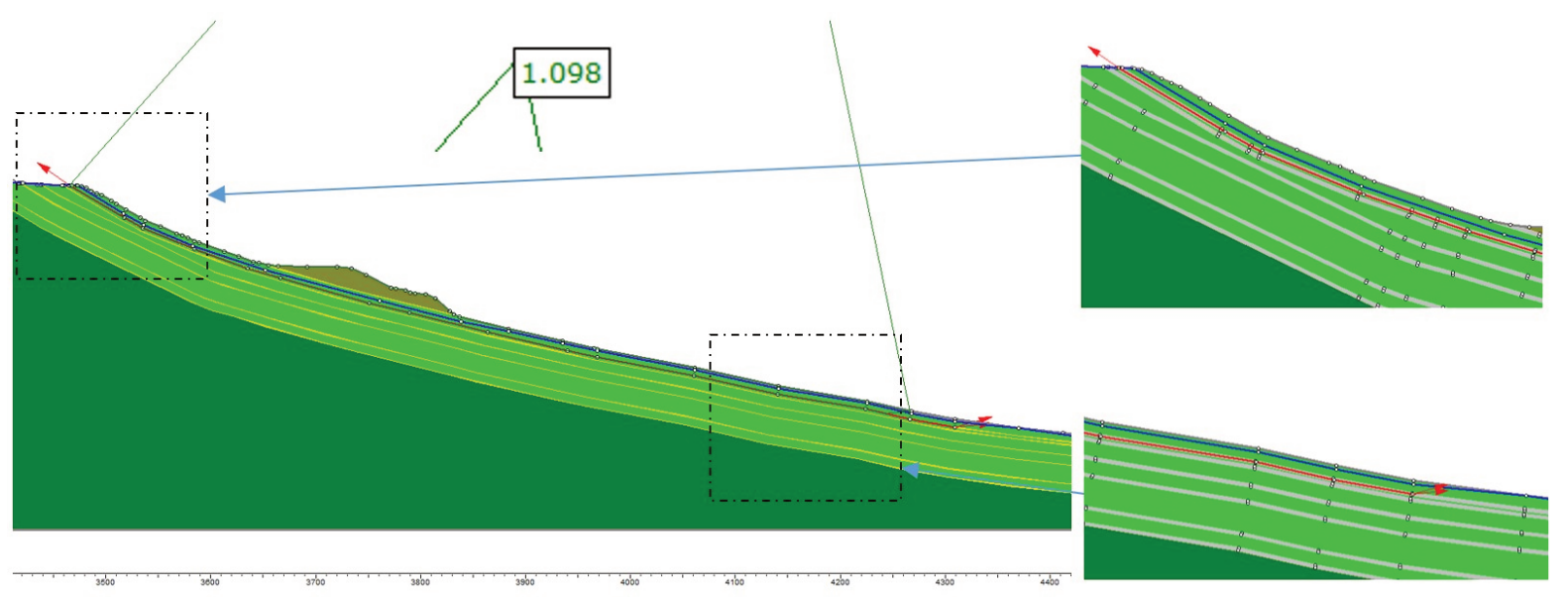

Figure 10 Back-analysis of creeping footwall and note depressurised footwall in crest area (upper right) and saturated at toe (lower right) 


\section{Conclusion}

Owing to the difficulty in reconciling Disturbance Factor, the approach the authors have utilised comprises:

- Estimate GSI based on RMR from core logging.

- Intact strength and mi estimates from laboratory testing.

- D value of zero.

- Accept the GSI value for highwall stability analyses and with GSI values in interburdens ranging from 55 to 65 .

- Based on the back-analyses of footwall instabilities, downrate the GSI value for the footwall toe in view of the impact of anisotropy on the rock mass strength. The authors have found that a reduction factor of the order of $70-80 \%$ to the GSI value based on RMR logging provides a reasonable starting point for designs (i.e. where an interburden has a GSI value of 55 , in the footwall stability analysis a GSI in the range of 39 to 44 would be assigned).

Caution is required in footwall analyses as the results are very sensitive to groundwater assumptions. As such, footwall designs require that a conservative view on potential groundwater scenarios be utilised and with appropriate consideration for depressurisation measures.

Good monitoring is required to understand deformations of both the surface of the slab and internal shear planes to confirm that the critical weak layer is in accord with the geotechnical model.

\section{Acknowledgement}

The authors acknowledge the assistance of Ross Seedsman on his assistance on the issues of anisotropy and conditions at the toe of the footwall.

The support of Prodeco management, their personnel and the opportunity to present this work is gratefully acknowledged.

\section{References}

Alejano, LR, Ferrero, AM, Ramırez-Oyanguren, P \& Alvarez Fernandez, MI 2011, 'Comparison of limit-equilibrium, numerical and physical models of wall slope stability', International Journal Rock Mechanics and Mining Sciences, vol. 48, pp. 16-26.

Bieniawski, ZT 1989, Engineering Rock Mass Classifications A Complete Manual for Engineers and Geologists in Mining, Civil and Petroleum Engineering, John Wiley and Sons.

Cavers, DD, Baldwin, GJ, Hannah, T \& Singhal, RK 1986, 'Design methods for open pit coal mine footwalls', Proceedings of the International Symposium on Geotechnical Stability in Surface Mining, pp. 79-86.

Cavers, DS 1981, 'Simple methods to analyse buckling of rock slopes', Rock Mechanics, vol. 14, pp. 87-104.

Coulthard, MA, Lucas, DS \& Fuller, PG 2004, 'Application of UDEC to a stress-related mine slope failure at Leigh Creek, South Australia', International Symposium of Numerical Modelling of Discrete Materials in Geotechnical Engineering, Civil Engineering, and Earth Sciences, A.A. Balkema, Rotterdam, pp. 289-296.

Duran, A \& Seedsman, RW 2018, 'Managing water pressures in a steeply dipping coal-mine footwall', Slope Stability 2018 - XIV International Congress on Energy and Mineral Resources, Asociación Nacional de Ingenieros de Minas, pp. 1436-1442.

Garzon, SER 2016, 'Analytical solution for assessing continuum buckling in sedimentary rock slopes based on the tangent-modulus theory', International Journal of Rock Mechanics and Mining Sciences, vol. 90, pp. 53-61.

Hawley, PM, Martin, DC \& Acott, CP 1986, 'Failure mechanics and design considerations for footwall slopes', CIM Bulletin, vol. 79, iss. 896, pp. 47-53.

Hoek, E \& Brown, ET 1980, 'Empirical strength criterion', Journal of the Geotechnical Engineering Division, vol. 106 (GT9), pp. 1013-1035.

Hoek, E \& Brown, ET 1997, 'Practical estimates of rock mass strength', International Journal of Rock Mechanics and Mining Sciences, vol. 34, iss. 8, pp. 1165-1186.

Hoek, E \& Brown, ET 2018, 'The Hoek-Brown failure criterion and GSI - 2018 edition', Journal of Rock Mechanics and Geotechnical Engineering, vol. 11, iss. 3, https://doi.org/10.1016/j.jrmge.2018.08.001

Hoek, E, Carranza-Torres, CT \& Corkum, B 2002, 'Hoek-Brown Failure Criterion- 2002 Edition', Proceedings of the 5th North American Rock Mechanics Symposium, pp. 267-273. 
Hoek, E, Marinos, PG \& Marinos, VP 2005, 'Characterisation and engineering properties of tectonically undisturbed but lithologically varied sedimentary rock masses', International Journal of Rock Mechanics and Mining Sciences, vol. 42, iss. 2, pp. $277-285$.

Krahn, J 2003, 'The 2001 R.M. Hardy Lecture: The limits of limit equilibrium', Canadian Geotechnical Journal, vol. 40, pp. 643-660.

Kutter, HK 1974, 'Mechanisms of slope failure other than pure sliding', in L Mueller (ed.), Rock Mechanics, CISM Courses and Lectures, p. 165, Springer, New York.

Mercer, KG 2012, 'The history and development of the anisotropic linear model: part 1', Newsletter Australian Centre for Geomechanics, Australian Centre for Geomechanics, vol. 38, July 2012, pp. 13-16, https://acg.uwa.edu.au/wpcontent/uploads/2014/12/NL38_web_ref.pdf

Mercer, KG 2013, Ongoing research into anisotropic rock masses using numerical modelling, in PM Dight (ed), Proceedings of the International Symposium on Slope Stability in Open Pit Mining and Civil Engineering (Slope Stability 2013), Australian Centre for Geomechanics, Perth, pp. 237-247.

Rose, ND, Scholz, J, Burden, J, King, M, Maggs, C \& Havaej, M 2018, 'Quantifying transitional rock mass disturbance in open pit slopes related to mining excavation', Slope Stability 2018 - XIV International Congress on Energy and Mineral Resources, Asociación Nacional de Ingenieros de Minas, pp. 1273-1288.

Seedsman, RW 2017, 'The spalling limit in transversely isotropic materials, the prediction of the maximum height of failure, and the design of long-tendon roof support systems', Mining Technology, https://doi.org/10.1080/14749009.2017.1325552

Stead, D \& Eberhardt, E 1997, 'Developments in the analysis of footwall slopes in surface coal mining', Engineering Geology, vol. 46, pp. 41-61.

Tokimoto, S \& Mercer, KG 2013, 'Preliminary review of the geotechnical characteristics and shear strength estimates of small scale anisotropic waveform formations of the Pilbara, Western Australia', in PM Dight (ed), Proceedings of the International Symposium on Slope Stability in Open Pit Mining and Civil Engineering (Slope Stability 2013), Australian Centre for Geomechanics, Perth, pp. 337-348. 
